Alemparte Barreda Asociados Arqtos Daw Arquitectos y Diseñadores

Arquitectos Manuel Wedeles (Alemparte y Barreda); Macarena Asuilar, Felipe Wedeles, Roberto Delpiano, Diego Aguilar (Daw)

Ubicación Calles de la comuna de Vitacura, Santiago Mandante Grupo Sarmiento S.A.

Cálculo estructural Manuel José Ruiz, ingeniero estructural

Construcción Maestranza Titán Ltda.

Materialidad Acero inoxidable, vidrio templado, madera

Cantidad de elementos 109 paraderos, 250 paletas publicitarias,

3 kioskos informativos

Superficie construida $5 \mathrm{~m}^{2}$ por paradero $\left(545 \mathrm{~m}^{2}\right.$

$6 \mathrm{~m}^{2}$ por paradero $\left(18 \mathrm{~m}^{2}\right)$

Año proyecto 2000

Año construcción 2001

\title{
Mobiliario urbano de Vitacura
}

La propuesta es consolidar, a través del equipamiento urbano, una imagen propia y unificadora de la comuna. Para el diseño del equipamiento, se tomaron los elementos que se desprenden de los análisis de antecedentes y que eran propios de Vitacura. Es así como el cóndor, el planeador y el cerro Manquehue se transformaron en objetos de observación y estudio por parte del equipo de diseño, logrando una visión de cómo debían aplicarse en la ornamentación del mobiliario.

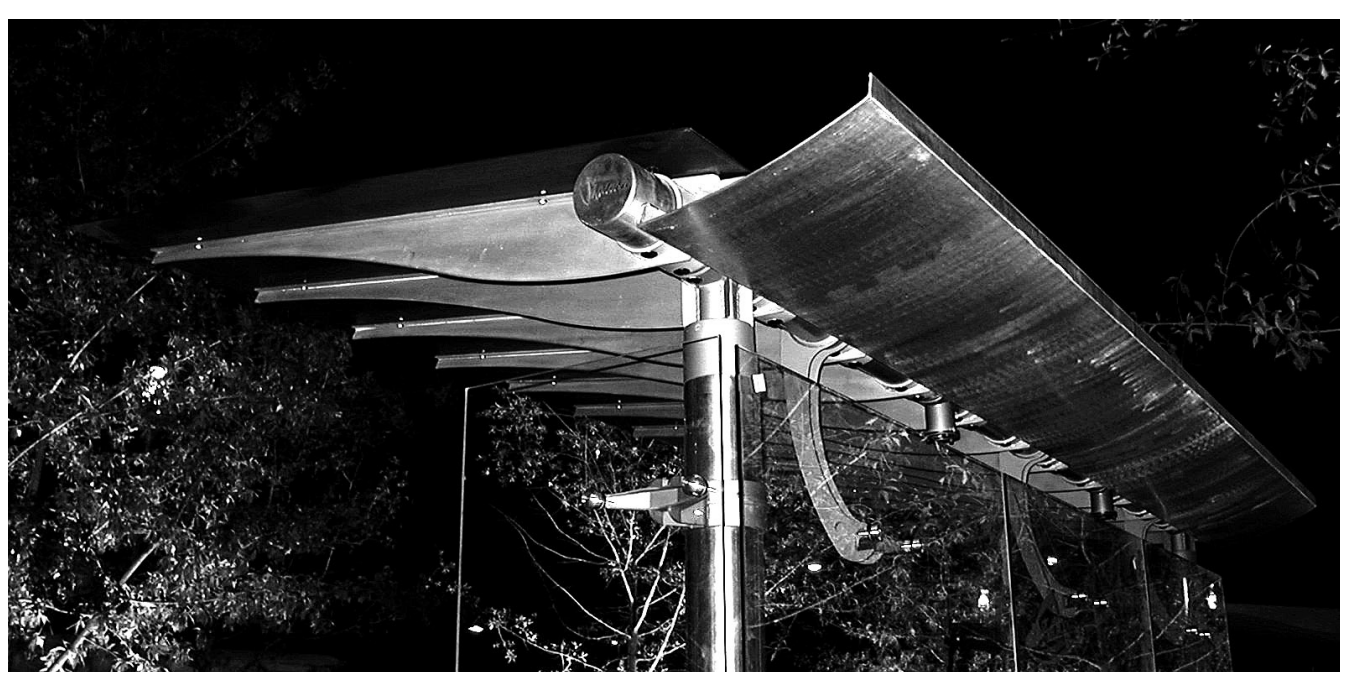

Alemparte Barreda Arquitectos Asociados

Oficina formada en 1953 e integrada por Sergio Alemparte A., Ernesto Barreda F., Manuel Wedeles G., Yves Besacon P. Entre sus obras destacan hoteles, edificios de oficina, viviendas, industrias, etc.

Daw Arquitectos y Diseñadores

Oficina formada en el 2000 e integrada por dos diseñadores y dos egresado de arquitectura de distintas universidades. Actualmente desarrollan proyectos de ambas áreas.

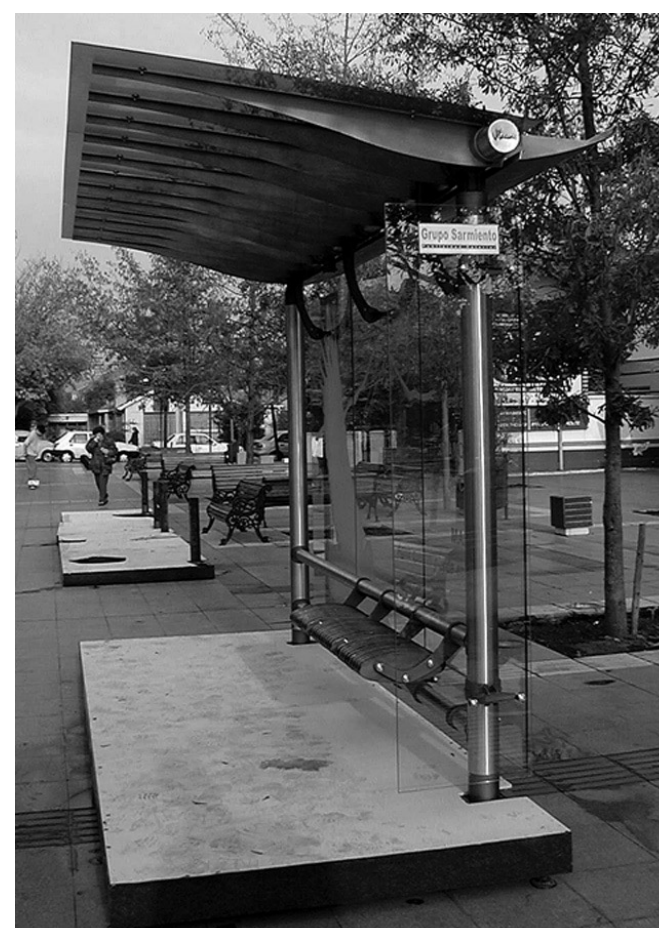

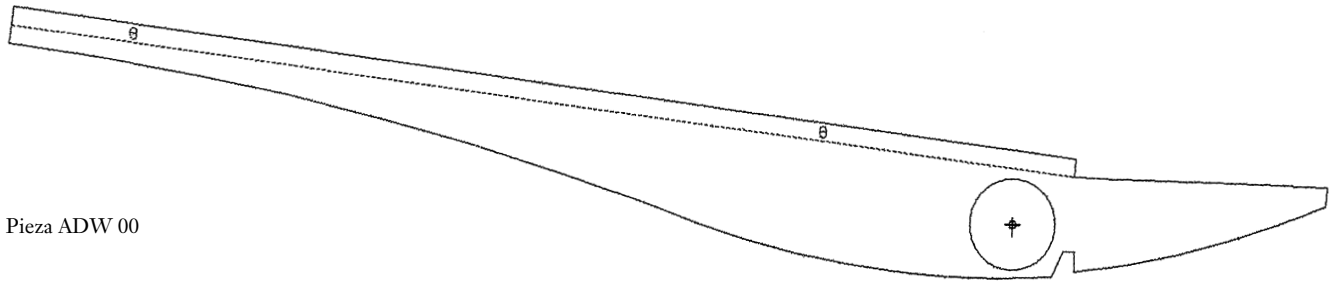

Tubo de fijeción para pieza ADW 00 ( tubo de cobre $3 \mathrm{~mm}$.)

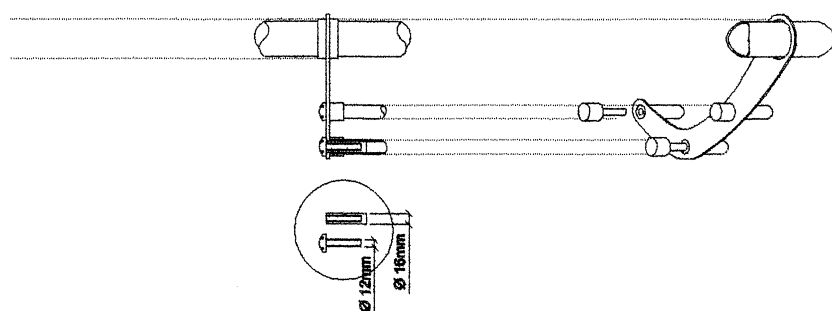

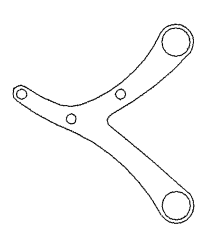

Pieza de unión HF 05

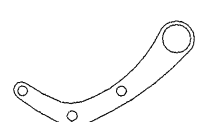

Pieza de unión HF 04
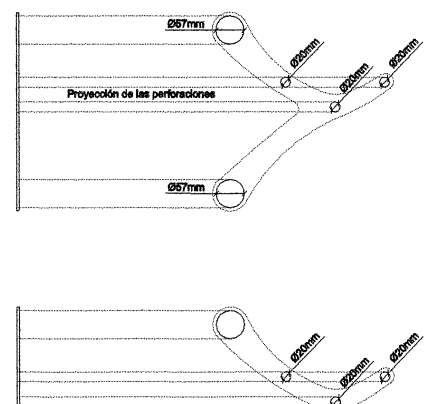